\title{
Perancangan Hotel Resort di Tepi Sungai Siak Kota Pekanbaru
}

\author{
Indra Alvino Marbun ${ }^{1}$, Hendri Silva ${ }^{2}, \operatorname{Imbardi}^{3}$ \\ 1,2,3 Program Studi Arsitektur, Fakultas Teknik, Universitas Lancang Kuning Pekanbaru. \\ Jl. Yos Sudarso km. 8 Rumbai, Pekanbaru, Telp. (0761) 52324 \\ Email: indra_alvino_marbun@yahoo.com, hsilva@unilak.ac.id, imbardi@unilak.ac.id
}

\begin{abstract}
ABSTRAK
Seiring dengan perkembangan dan pertumbuhan bisnis di Kota Pekanbaru telah mendorong pertumbuhan akomodasi bisnis perhotelan. Pembangunan akomodasi perhotelan di Pekanbaru mengalami peningkatan, akan tetapi hotel yang ada di Pekanbaru rata-rata hotel bisnis. Pada jaman sekarang manusia moderen pada dasarnya cenderung membutuhkan rekreasi untuk dapat bersantai dan menghilangkan kejenuhan yang diakibatkan oleh aktivitas mereka. Keberadaan potensi alam yang indah dan sejuk sangat sulit didapatkan didaerah perkotaan yang penuh sesak dan polusi udara. Dengan demikian keinginan masyarakat perkotaan untuk menikmati potensi alam menjadi permasalahan. Dengan melihat permasalahan ini maka muncul sebuah gagasan untuk membangun Hotel Resort wisata, yaitu Hotel Resort yang berada di daerah tepian Sungai Siak Kota Pekanbaru, dengan memanfaatkan potensi Sungai Siak yang sudah ada. Sejauh ini pemanfaatan Sungai Siak hanya sebatas sebagai transpotrasi air saja, sangat disayangkan jika tidak memanfaatkan potensi sungai terbesar di Indonesia yang ada di Kota Pekanbaru ini.
\end{abstract}

Kata Kunci : Rekreasi, Hotel Resort.

\begin{abstract}
Along with the development and business growth in Pekanbaru City has encouraged the growth of hotel business accommodation. The development of hotel accommodation in Pekanbaru has increased, but the existing hotels in Pekanbaru are an average business hotel. In modern times modern humans basically tend to need recreation to be able to relax and eliminate the saturation caused by their activities. The existence of beautiful and cool natural potential is very difficult to get in the crowded urban areas and air pollution. Thus the urban community's desire to enjoy the potential of nature becomes a problem. By looking at this problem then came an idea to build Hotel Resort tour, the Hotel Resort located on the banks of the River Siak Pekanbaru, by exploiting the potential of Siak River that already exists. So far the utilization of Siak River is only limited as water transpotrasi only, very unfortunate if not exploiting the largest river potential in Indonesia in this Pekanbaru city.
\end{abstract}

Keywords: Recreation, Resort Hotel.

Indra Alvino Marbun , Perancangan Hotel Resort di Tepi Sungai Siak Kota Pekanbaru 


\section{PENDAHULUAN}

Kota Pekanbaru adalah ibu kota Provinsi Riau, Indonesia. Kota ini merupakan kota perdagangan dan jasa, termasuk sebagai kota dengan tingkat pertumbuhan, migrasi dan urbanisasi yang tinggi. Provinsi Riau khususnya Kota Pekanbaru sangat pesat melakukan pengembangan infrastruktur. Kota Pekanbaru sebagai pusat segala kegiatan di Provinsi Riau memiliki visi menuju "Pekanbaru sebagai kota metropolitan yang madani pada tahun 2025 ". Yang salah satu Misi nya yang berbunyi, "Meningkatkan infrastruktur daerah baik prasarana jalan, air bersih, energi listrik, penanganan limbah yang sesuai dengan kebutuhan daerah terutama infrastruktur pada kawasan industri, pariwisata serta daerah pinggiran kota".

Seiring dengan perkembangan dan pertumbuhan pariwisata di daerah Riau telah mendorong pertumbuhan akomodasi pariwisata pada umunya dan bisnis perhotelan pada khusunya. Pembangunan akomodasi perhotelan di Pekanbaru mengalami peningkatan, tetapi hotel yang ada di Pekanbaru rata-rata hotel bisnis.

Namun pada kenyataannya hotel bukan lagi sebagai tempat bermalam saja tetapi sudah berkembang sebagai tempat untuk beristirahat dan rekreasi. Tuntutan wisatawan itu menghendaki hotel yang dapat memenuhi kebutuhan akan privasi, kontak dengan alam dan pengalaman unik yang berkesan.

Manusia modern pada dasarnya cenderung membutuhkan rekreasi untuk dapat bersantai dan menghilangkan kejenuhan yang diakibatkan oleh aktivitas mereka. Keberadaan potensi alam yang indah dan sejuk sangat sulit didapatkan didaerah perkotaan yang penuh sesak dan polusi udara. Dengan demikian keinginan masyarakat perkotaan untuk menikmati potensi alam menjadi permasalahan.

Secara Geografis kondisi alam Pekanbaru tidak memiliki potensi alam yang cukup menarik, dan tanah yang relatif datar. Sehingga keinginan masyarakat untuk menikmati potensi alam susah didapatkan terlebih di kota Pekanbaru. Dalam hal ini direncanakan membangun sebuah hotel di Kota Pekanbaru dengan memanfaatkan potensi alam yang sudah ada yaitu Sungai Siak, mengingat Kota Pekanbaru dilintasi oleh sebuah sungai terbesar yang ada di Indonesia. Dan sekarang beberapa jembatan besar telah dibangun sebagai penghubung jalan yang dipisahkan oleh Sungai Siak tersebut, potensi ini cukup baik untuk mendukung prasarana untuk berinvestasi suatu akomodasi wisata seperti resort hotel. Seperti yang diketahui belum cukup maksimalnya pemerintah dan investor yang ada untuk memanfaatkan potensi di area tepian Sungai Siak ini. Dengan melihat banyaknya lahan yang belum dikekola dengan baik di daerah tepian Sungai Siak ini maka tercetuslah gagasan untuk membangun sebuah Hotel Resort wisata di daerah tepian Sungai Siak ini dengan memanfaatkan potensi Sungai Siak yang sudah ada. Sejauh ini pemanfaatan Sungai Siak hanya sebatas sebagai transpotrasi air saja, sangat disayangkan jika tidak memanfaatkan potensi sungai terbesar di Indonesia yang ada di Kota Pekanbaru ini. Hotel Resort ini merupakan hotel yang menawarkan berbagai macam fasilitas dan pelayanan termasuk rekreasi yang memanfaatkan potensi alam tersebut.

\section{METODE PENELITIAN}

Metode yang digunakan untuk mendapatkan data-data yang terkait dengan perancangan "Perancangan Hotel Resort Di Tepi Sungai Siak Kota Pekanbaru" ini adalah dengan metode penelitian berdasarkan aspek sebagai berikut :

1. Aspek Tapak,

2. Aspek Manusia, dan

3. Aspek Lingkungan

\section{HASIL PENELITIAN}

Lokasi Pada Tapak Perancangan Hotel Resort Di Tepi Sungai Siak Kota Pekanbaru. Lokasi tapak yang akan digunakan untuk perancangam ini berada di WP III yaitu di daerah Kecamatan Rumbai Pesisir tepatnya di Jl.Sembilang, dengan luas tapak yang direncanakan sekitar $\pm 31.4 \mathrm{Ha}$.

Indra Alvino Marbun , Perancangan Hotel Resort di Tepi Sungai Siak Kota Pekanbaru 


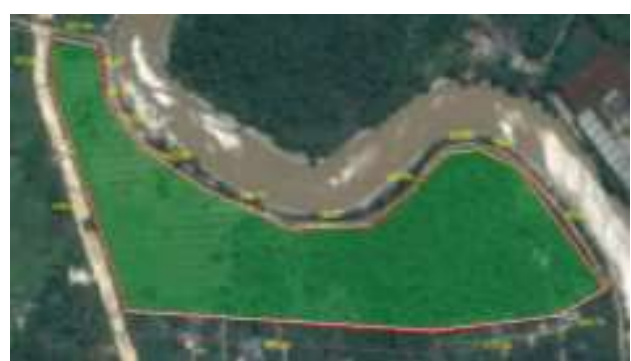

Gambar 1. Tapak Hotel Resort

\section{Kondisi dan Batasan Tapak}

Kondisi pada tapak memiliki tanah rawa dan ditumbuhi oleh semak belukar.

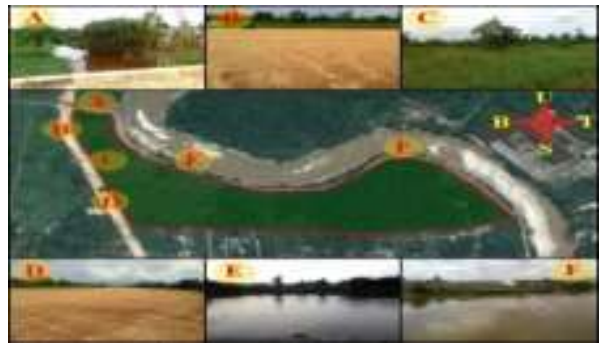

Gambar 2. Kondisi dan Batasan Tapak

\section{Akses Jalan Yang Ada Disekitar Tapak}

Untuk pencapaian ke lokasi tapak dapat dilakukan dengan menggunakan akses darat dan air. Adapun dengan akses darat dapat dicapai dengan transportasi kendaraan umum, kendaraan pribadi maupun pejalan kaki melalui Jl.Sembilang. Dan akses air dapat ditempuh dengan menggunakan transportasi air seperti boat melalui Sungai Siak.

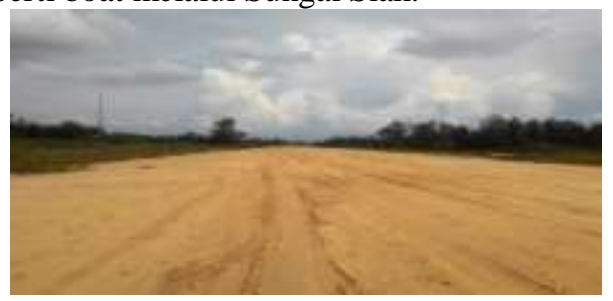

Gambar 3. Akses darat Jl.Sembilang

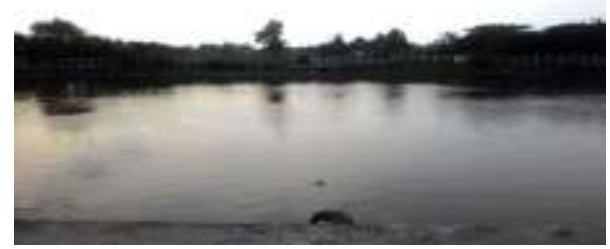

Gambar 4. Akses Air Sungai Siak

\begin{abstract}
Aspek Manusia
Aspek manusia merupakan hal yang terpenting bagi seorang perancang dalam merancang sebuah bangunan, karena manusia merupakan pengguna dari pada bangunan tersebut. Diharapkan perancang dapat merancang sesuai dengan kriteria dan kebutuhan manusia sebagai pengguna bangunan.
\end{abstract}

Faktor manusia sangat penting diperhatikan saat mendesain sebuah bangunan, hal ini sangat berpengaruh terhadap ruang-ruang yang akan kita butuhkan. Pada faktor manusia ini terdapat 3 aspek yang sangat penting, yaitu

1.Pelaku Kegiatan,
a) Tamu Hotel Resort
b) Pengunjung Hotel Resort
c) Pengelola Hotel Resort
d) Staff / Karyawan Hotel Resort

2.Aktivitas Pelaku,

a) Tamu Hotel Resort

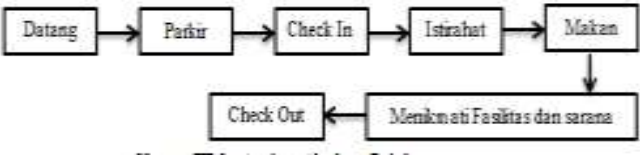

Skema 1. Analisa Aktifitas Pelaku

b) Pengunjung Hotel Resort

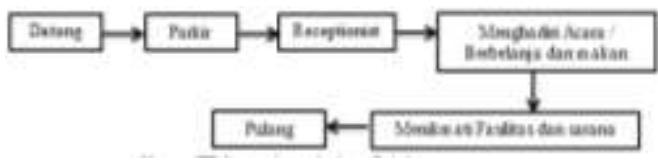

Skema 2. Analisa Aktifitas Pelaku

c) Pengelola Hotel Resort

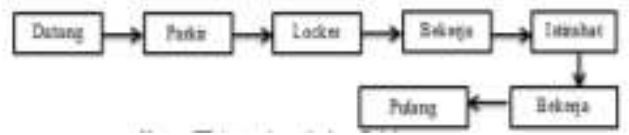

Skema 3. Analisa Aktifitas Pelaku 
d) Staff / Karyawan Hotel Resort

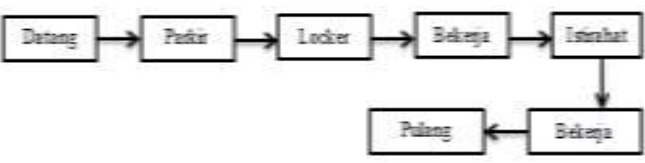

Skema 4. Analisa Aktifitas Pelaku

3.Kebutuhan Ruang.

Tabel III.1. Kebutuhan Ruang

\begin{tabular}{|c|c|c|c|}
\hline Sh & Protakn & Krusean & Ketiutebas Rane \\
\hline t & Penatón & 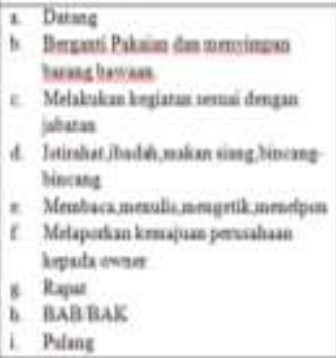 & 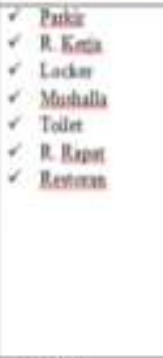 \\
\hline 2 & $\begin{array}{l}\text { Salt } \\
\text { Kacowa }\end{array}$ & 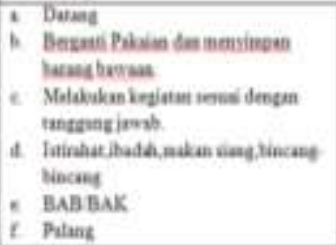 & 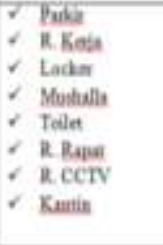 \\
\hline
\end{tabular}

Tabel III.2. Kebutuhan Ruang

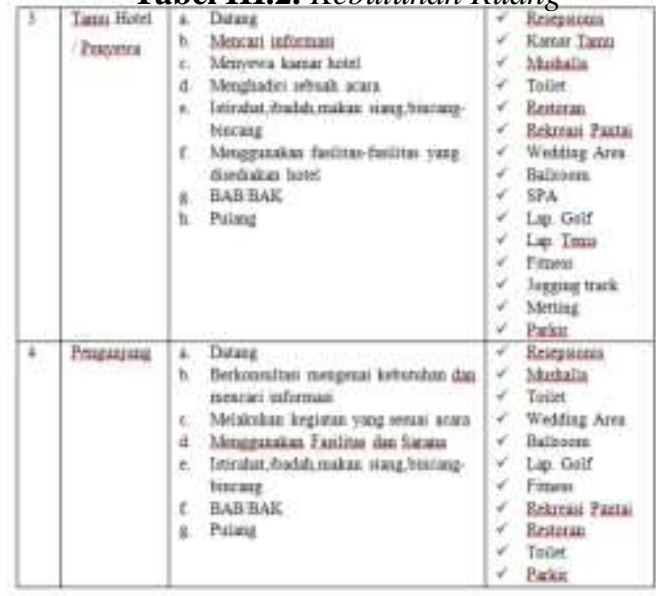

Analisa Tapak dan Dimensi Tapak

Lokasi tapak yang akan digunakan untuk perancangam ini berada di WP III yaitu di daerah Kecamatan Rumbai Pesisir tepatnya di Jl.Sembilang, dengan luas tapak yang direncanakan sekitar $\pm 31.4 \mathrm{Ha}$.

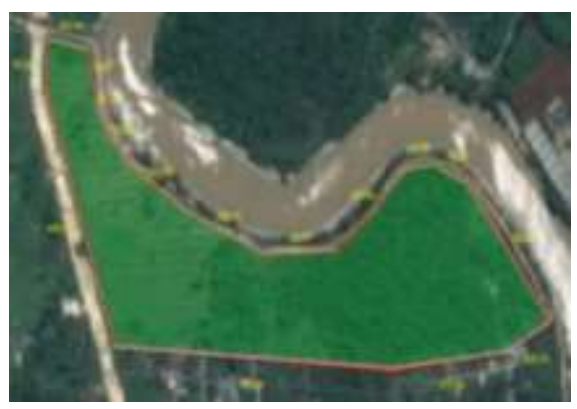

Gambar 5. Tapak Hotel Resort

\section{Batas Batas Tapak}

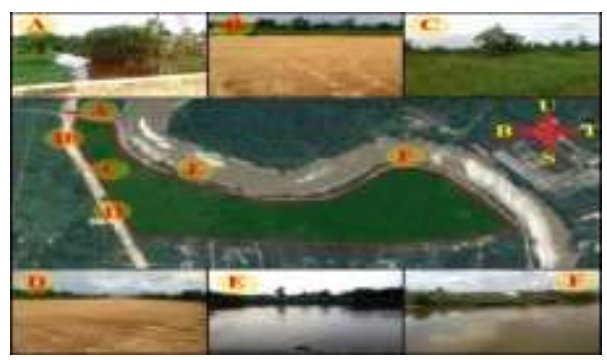

Gambar 6. Batas Tapak

\section{Analisa Pencapaian Tapak}

Untuk pencapaian ke lokasi site dapat dilakukan dengan menggunakan akses darat dan air.

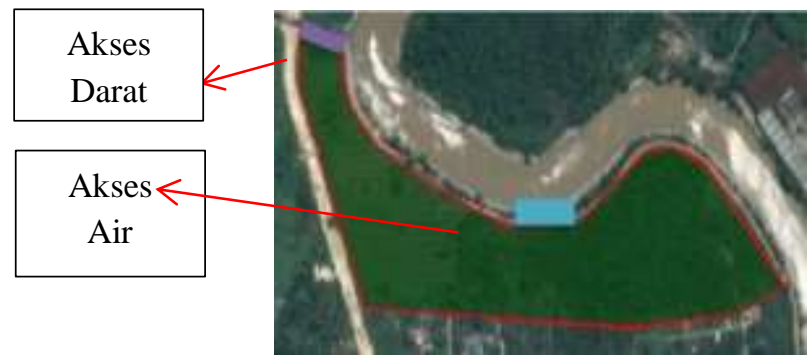

Gambar 7. Pencapaian Tapak

\section{Analisa Kebisingan}

Dalam analisa kebisingan pada tapak hanya ada satu sumber kebisingan yang terletak di area akses jalan utama pada area tapak ini. Untuk mengatasi sumber kebisingan ini, maka ada beberapa cara untuk mengatasi nya, yaitu

1. Pada area sumber kebisingan akan di berikan pohon peneduh sebagai peredam kebisingan yang disebabkan oleh kendaraan yang melintasi jalan utama ini. 
2. Untuk area privat yang membutuhkan ketenangan seperti kamar dan villa pada hotel resort ini akan dijauhkan penzoningannya dari sumber kebisingan.

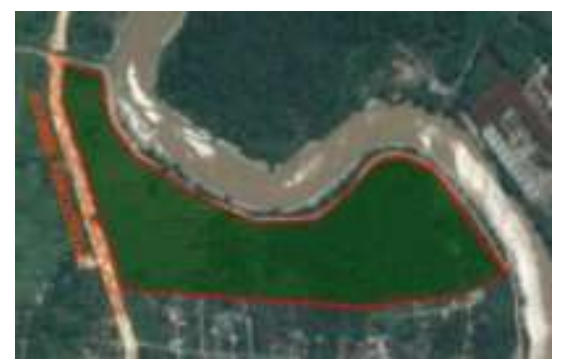

Gambar 8. Sumber Kebisingan

\section{Analisa Orientasi Matahari}

Arah orientasi matahari yang sangat berpengaruh terhadap kondisi lingkungan sekitar maupun aktifitas yang terjadi di dalam bangunan. Pada arah orientasi matahari terbit dan terbenam nanti akan direncanakan peletakan zoning pengelola, bangunan utama dan unit hunian yang bertujuan untuk mendapatkan suasana matahari terbit dan terbenam pada masing - masing waktu orientasi matahari tersebut. Suasana ini bertujuan untuk mendukung suasana pada hotel resort di area danau dan area pantai buatannya. Dan untuk antisipasi dampak panas dari sinar matahari langsungnya dilakukan cara sebagai berikut :

A. Menggunakan Sun Shading pada bangunan guna mencegah panas sinar matahari langsung masuk kedalam bangunan.

B. Meminimalkan bukaan jendela pada bagian bangunan yang terkena sinar matahari.

C. Penempatan pepohonan didalam site yang berguna mengurangi panas sinar matahari pada sekitar bangunan dan membuat daerah sekitar teduh.

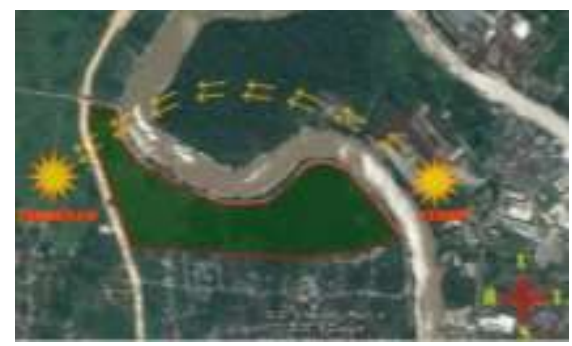

Gambar 9. Orientasi Matahari

\section{Analisa Potensi View}

Dalam analisa potensi view pada tapak terdapat view terbaik pada tapak yaitu ke arah sungai, potensi ini merupakan menjadi salah satu syarat untuk di bangunnya hotel resort ini. Dalam orientasi view pada tapak akan di pusatkan kearah sungai untuk mendapatkan suasana dan view yang terbaik. Pada area ini akan ditempatkan zoning fasilitas penunjang dan unit hunian.

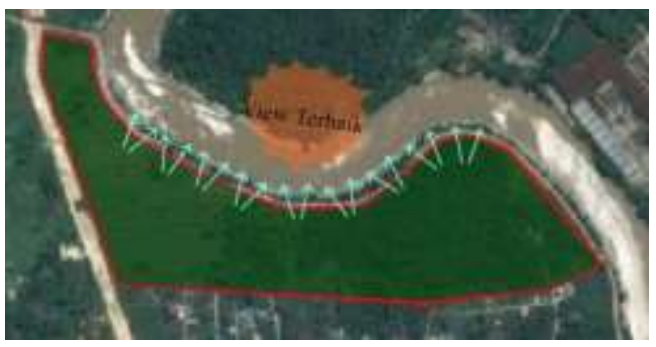

Gambar 10. Potensi View

\section{Analisa Penzoningan Tapak}

Penzoningan pada tapak dikelompokan berdasarkan beberapa bagian berikut :
a. Zona parkir dan dermaga
b. Zona massa bangunan utama dan pengelola
c. Zona rekreasi dan fasilitas penunjang
d. Zona unit hunian
e. Zona taman
f. Zona servis

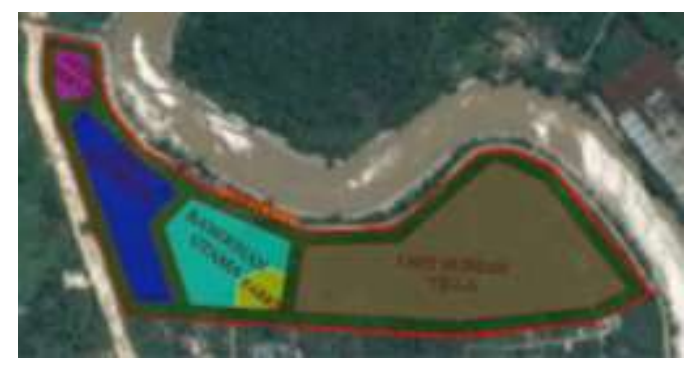

Gambar 11. Penzoningan Tapak

\section{Analisa Vegetasi Tapak}

Pola tata hijau ditentukan sebagai elemen pendukung untuk memperindah site dan juga dapat menciptakan suasana iklim yang sejuk serta dapat melindungi bangunan dari sengatan sinar matahari. Vegetasi juga bertujuan untuk sebagai pemecah angin dan penghawaan alami. Penetapan pola vegetasi mempunyai fungsi sebagai berikut :

1. Fungsi estetis : tanaman sebagai memperindah pandangan dan mampu menyatukan massa.

2. Fungsi teknis : tanaman sebagai pelindung dan memberikan suasana kesejukan pada bangunan, manusia 
dan tanah terhadap pengaruh panas yang berlebihan.

3. Fungsi pendukung : sebagai pengarah sirkulasi dan batas pandang.

\section{Analisa Regulasi Tapak}

Berdasarkan tabel regulasi peraturan daerah kota Pekanbaru no 14 tahun 2000 tentang izin mendirikan bangunan didapatkan bahwa standar regulasi mendirikan bangunan untuk Hotel Resort ini adalah sebagai berikut :

$$
\begin{array}{ll}
\text { KDB } & : 50 \% \\
\text { KLB } & : 0.50 \\
\text { GSB } & : 20 \text { meter muka, } 6 \text { meter }
\end{array}
$$

belakang, 4 meter samping

$$
\begin{array}{ll}
\text { GSS } & : 5 \text { meter } \\
\text { Luas tapak } & : \mathbf{3 1 . 4} \mathbf{~ H a}
\end{array}
$$

Berdasarkan ketentuan diatas, maka didapatkan perhitungan sebagai berikut.

a. Luas lantai dasar yang diizinkan

$=\mathrm{KDB} \times$ luas tapak

$=50 \% \times 31.4 \mathrm{Ha}$

$=15.7 \mathrm{Ha}$

b. Luas lantai bangunan yang dizinkan

$=$ KLB $x$ luas lahan

$=0.5 \times 31.4 \mathrm{Ha}$

$=15.7 \mathrm{Ha}$

\section{Analisa Berdasarkan Topik dan Tema}

Tema pada perancangan ini adalah Penerapan Prinsip-Prinsip Nilai Arsitektur Melayu Tepi Air Pada Bangunan Hotel Resort, dan Topik perancangannya Arsitektur Tepi Air (Waterfront). Penerapan tema dan topik pada bentuk bangunan hotel resort ini akan diterapkan pada semua bangunan yang ada pada site ini, dan nantinya pada bangunan utama akan mengadopsi unsur post modern pada bangunan melayu nya yaitu dengan mengambil beberapa unsur elemen pembentuk dari Rumah Melayu yang ada di Riau.

\section{Analisa Sistem Struktur}

Sistem struktur yang akan digunakan nantinya dapat dibagi menjadi 3 kelompok, yaitu :

1. Sub Struktur, merupakan struktur paling bawah, yaitu pondasi. Berfungsi sebagai penopang seluruh beban yang ada diatasnya. Pondasi yang akan digunakan yaitu pondasi tiang pancang dan cor beton bertulang, karena tapak merupakan tanah rawa.

2. Middle Struktur, merupakan struktur bagian tengah, dibagi atas :

\footnotetext{
- Struktur horizontal,
}

Struktur horizontal yaitu struktur plat lantai dan balok, berfungsi sebagai penahan beban yang ada diatasnya dan beban sendiri yang disalurkan pada struktur vertikal.

\section{- $\quad$ Struktur vertikal}

Struktur vertikal ialah struktur kolom, berfungsi untuk menyalurkan beban sendiri maupun beban yang ada diatasnya menuju pondasi.

3. $U p$ struktur, $U p$ struktur merupakan rangka atap, dalam hal ini bangunan akan menggunakan struktur rangka atap kombinasi. Yaitu dengan rangka baja ringan (spaceframe) dan atap dak beton bertulang.

\section{Konsep Dasar Perancangan}

Konsep dasar pada "Perancangan Hotel Resort Di Tepi Sungai Siak Kota Pekanbaru”, ini berangkat dari visi kota Pekanbaru dengan pendekatan yang berlandasan pada topik "Arsitektur Tepi Air" dengan tema "Penerapan Prinsip-Prinsip Nilai Arsitektur Melayu Tepi Air Pada Bangunan Hotel Resor'. Pendekatan dengan topik Arsitektur tepi air ini merupakan tanggapan dari respon tapak ke sirkulasi dan penzoningan pada bentuk perancangan bangunan hotel resort. Sedangkan penerapan tema dalam perancangan ini di tujukan pada pengolahan pola ruang dan suasana pada hotel resort ini.

\section{Konsep Hotel Resort}

Adapun konsep hotel resort yang ingin di bangun disini yaitu dengan memanfaatkan dari potensi tapak yang ada yaitu tapak yang masih mempunyai potensi alam yaitu sungai dan dengan menambahkan beberapa potensi unsur - unsur alam pembentuk hotel resort lainnya seperti :
a. Pantai buatan,
b. Sungai buatan,
c. Promonade, dan
d. Area hutan 


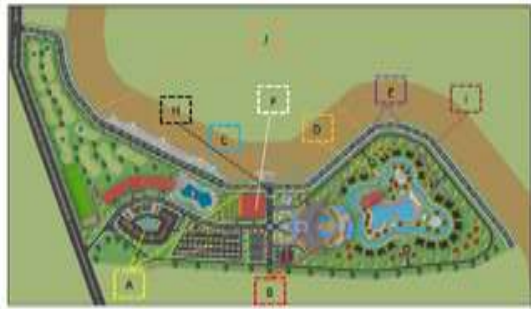

Gambar 12. Konsep Hotel Resort

\section{Konsep Besar Perancangan Hotel Resort}

Konsep besar dari perancangan ini terdiri dari konsep sirkulasi, penzoningan, orientasi dan gubahan massa pada perancangan tapak dikelompokan berdasarkan beberapa bagian berikut :

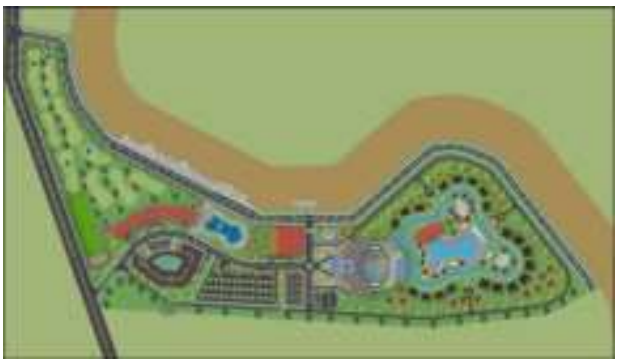

Gambar 13. Konsep Besar Hotel Resort

A. Zona Parkir dan Dermaga

Zona parkir dan dermaga di letakkan pada posisi yang mudah dicapai yaitu terletak dekat dari akses jalan utama pada tapak dan akses air dari sungai pada tapak, hal ini untuk memudahkan sirkulasi masuk dan keluar pada tapak, dan area parkir ini dijauhkan posisi nya dari zoning lainnya agar tidak memberikan kesan semak pada hotel resort dengan kelihatannya area parkir pada zoning lainnya akan memberikan kesan semak dan jauh dari kesan asri yang bernuansa alam pada hotel resort.

B. Zona Bangunan Utama dan Pengelola

Zona ini diletakkan di tengah - tengah tapak bertujuan untuk jadi area pembatas antara area semi public dan area privat. Area ini berdekatan dengan area parkir dan dermaga, yang berfungsi untuk memudahkan akses sirkulasi masuk dan keluar manusia dari zoning tersebut.

\section{Zona Rekreasi}

Zona ini terletak di sebelah atas tapak dari zona bangunan utama, yang bertujuan sebagai zona strategis untuk rekreasi dan fasilitas penunjang lainnya dikarenakan dengan alasan potensi view yang lebih baik diarea ini yang mengarah ke sungai untuk suasana yang lebih hidup bernuansa alam tepi air. Pada zona rekreasi ini akan diberikan konsep pantai buatan.

D. Zona Sungai Dalam Tapak

Zona ini sebagai fasilitas penunjang luar pada dalam tapak yang nantinya akan dimanfaatkan sebagai akses sirkulasi untuk menuju ke unit - unit cottage yang tersebar di area ini agar lebih menghidupkan suasana melayu tepi air pada area ini. Dan zona ini juga sebagai pemisah dari area semi publik ke area privat unit hunian cottage.

E. Zona Unit Hunian

Untuk zona privat unit hunian cottage diletakkan di area zona sirkulasi sungai pada dalam tapak agar dapat menghidupkan suasana melayu tepi air, sehingga membuat zona ini berorientasi pada area sungai.

F. Zona Fasilitas Penunjang Area Unit Hunian

Untuk zona penunjang unit hunian ini sendiri diletakkan pada area yang berdekatan dari unit hunian. Pada zona ini diberikan fasilitas seperti pantai buatan,wedding area,jogging track, dan restoran khusus tamu pengunjung cottage.

G. Zona Vegetasi

Untuk zona Vegetasi sendiri diletakkan disetiap area pada tapak ini yang bertujuan untuk memberikan kesan nuansa alam pada hotel resort ini.

H. Sirkulasi Ruang Luar

Untuk sirkulasi luar pada perancangan ini dapat dicapai dari sirkulasi masuk pada tapak yang 
menuju ke parkir atau dari dermaga dan menuju ke bangunan utama.

I. Sirkulasi Ruang Dalam

Untuk sirkulasi ruang dalam pada perancangan ini dikhususkan untuk akses sirkulasi ke area unit hunian cottae dengan pencapaian sirkulasi pada kanal yang ada di area sungai. Sirkulasi di pisahkan pada area lainnya karna area hunian cottage ini adalah area unit privasi.

J. Fasilitas Penunjang Luar Olahraga

Orientasi fasilitas ini di letakkan di area pinggir sungai untuk mendapatkan view ke arah sungai dan nantinya lapangan ini berorientasi ke arah utara dan selatan untuk menghindari cahaya silau matahari dari arah orientasi matahari timur - barat.

\section{KESIMPULAN DAN SARAN}

\section{Konsep Perwujudan Bangunan Hotel Resort} Dengan Arsitektur Melayu Tepi Air

Pada konsep perwujudan bangunan hotel resort ini mengadaptasi beberapa elemen pembentuk dari rumah tradisional melayu yang ada di Provinsi Riau, yaitu pada bangunan utama akan mengadopsi bentuk transformasi post modern bangunan melayu dengan elemen panggung dan ukirannya.

Dan pada bentuk perwujudan bangunan pada unit hunian villa akan mengadopsi bentuk rumah tradisional melayu yang ada di Provinsi Riau saja, seperti, Rumah Melayu Atap Limas (Kabupaten Kampar, Kuansing dan Rohul).

\section{Konsep Ruang Dalam}

Pada konsep ruang dalam akan mengikuti fungsi hotel resort dan memadupadankan dengan bentuk rumah tradisional melayu yang akan diadopsi pada perancangan ini.

\section{Konsep Ruang Luar}

Konsep ruang luar bangunan ialah mampu menjadikan ruang terbuka sebagai daya tarik kawasan dan pengunjung, sehingga konsep ruang luar ini diterapkan dengan cara membuat adanya keterkaitan antara bangunan dan kawasan secara harmoni atau kontekstual sehingga mampu menciptakan suasana kampung melayu Riau dengan adanya beberapa rumah melayu di perancangan ini.

\section{Hasil Perancangan Hotel Resort Di Tepi Sungai Siak Kota Pekanbaru}

'Perancangan Hotel Resort Di Tepi Sungai Siak Kota Pekanbaru" yaitu Perancangan suatu jenis akomodasi yang terletak di pinggir kota yang menyediakan jasa penginapan, makan dan minum, sarana fasilitas pelengkap lainnya serta jasa yang dapat mendukung dan memperlancar kegiatan istirahat para tamu dengan memanfaatkan potensi sumber daya alam air Sungai Siak dan tata lingkungannya untuk bertujuan berwisata/berekreasi di hotel tersebut.

Harapannya pada 'Perancangan Hotel Resort Di Tepi Sungai Siak Kota Pekanbaru" ini bisa dijadikan wacana dan terealisasi agar dapat terwadahinya kegiatan rekreasi menginap hotel resort untuk masyarakat lokal maupun dari luar Kota

$\begin{array}{lrr}\text { Pekanbaru } & \text { dan juga dapat } \\ \text { membangkitkan } & \text { perekonomian } & \text { dan }\end{array}$
pariwisata.

Dengan adanya hotel resort ini dapat memberikan perkembangan infrastruktur Kota Pekanbaru serta terciptanya suatu tempat yang dapat menampung kegiatan rekreasi dan pariwisata.

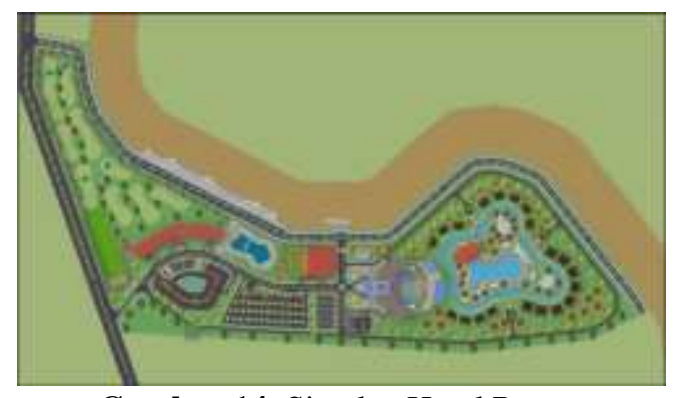

Gambar 14. Siteplan Hotel Resort

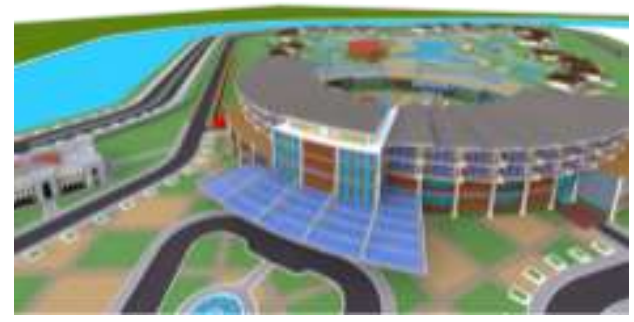

Gambar 15. Perspektif Hotel Resort 

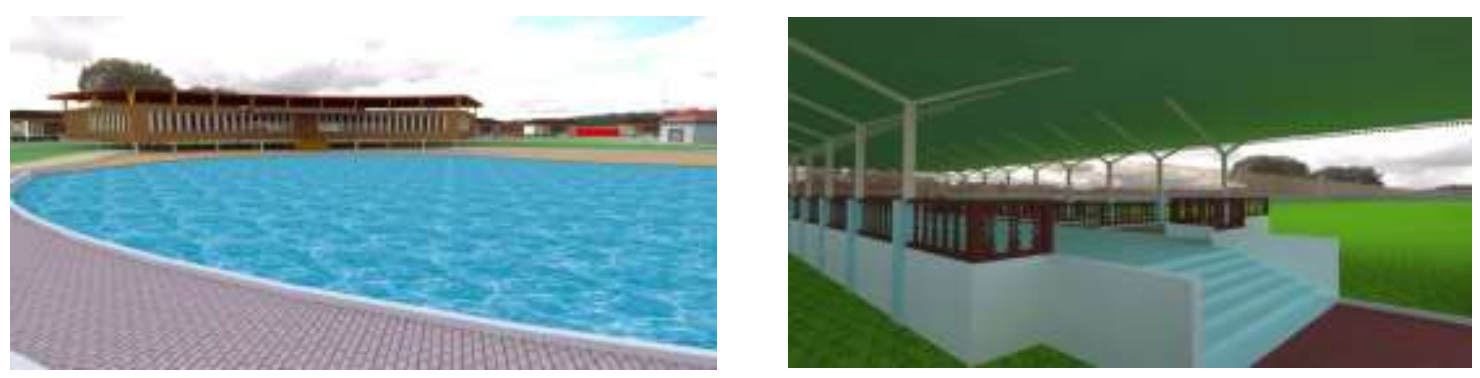

Gambar 16. Perspektif Hotel Resort

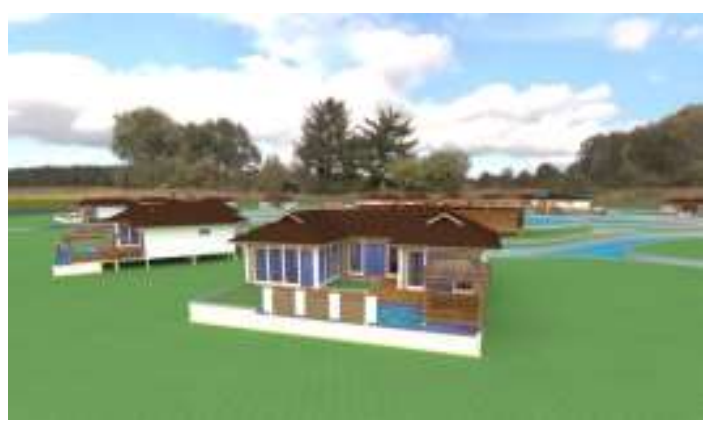

Gambar 17. Perspektif Cottage Hotel Resort

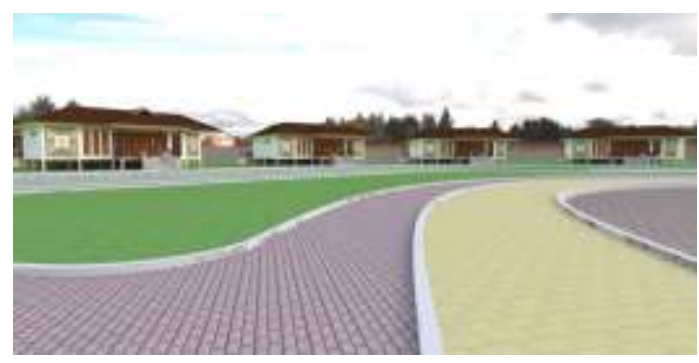

Gambar 18. Perspektif Cottage Hotel Resort

Gambar 19. Perspektif Restoran Hotel Resort

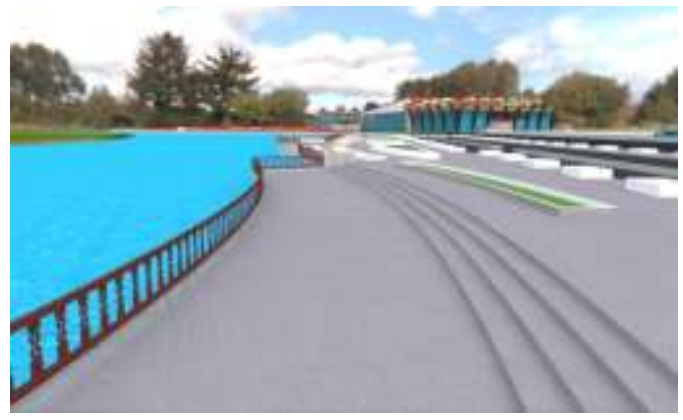

Gambar 20. Area Waterfront Hotel Resort

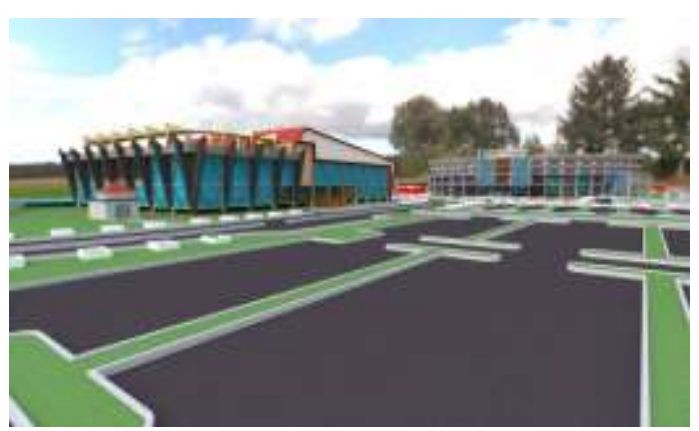

Gambar 21. Driving Range Golf Hotel Resort 


\section{DAFTAR PUSTAKA}

[1] John Wade, 1997. (Architecture, Problems and Purphoses). Pengertian Perancangan. Dirjen Pariwisata Pariwisata Tanah air Indonesia hal 13 November 1988.

[2] Yanti puspita : Perencanaan Hotel resort di Kawasan Teluk Kendari.

[3] Echols, 2003. Waterfront city Development.

[4] Wrenn,1983. Urban Waterfront.

[5] Prabudiantoro, 1997. Kriteria umum penataan dan Waterfront.

[6] Kurniasih, 2009. karakteristik Resort hotel.

karakteristik Resort hotel yang membedakannya dengan jenis hotel lain.

[7] Fred Lawson, 1995. Hotel and Resort, Planning, Design and Refubishment. prinsip-prinsip desain dalam perencanaan sebuah hotel resort.

[8] Yolanda Fransiska,Jurnal Jenis pelaku yang terdapat dalam hotel resort. Bappeda Provinsi Riau 2012 Peta Wilayah Pengembangan Kota Pekanbaru.

Dinas tata ruang dan wilayah kota pekanbaru.

[9] Peraturan KDB,KLB Wilayah Kota Pekanbaru.

[10] T.White,Edward.1983.Site Analysis

Menganalisa potensi Site yang ada disekitar.

[11] Neufert, Ernst.1991.DataArsitek Edisi 33 jilid 1 dan 2. Dimensi Manusia dan Ruang Interior. 